\title{
Control and optimization of parameters in the ESEM at high temperatures
}

\author{
S. Subramaniam, R.D. Roseman, \\ Department of Chemical and Materials Engineering, University of Cincinnati, M.L. 0012, \\ Cincinnati, $\mathrm{OH} 45221-0012$
}

High temperature processes play a decisive role in microstructure and property development of engineering materials. A fundamental understanding of the behavior of materials at elevated temperatures must precede control and optimization of these processes in advanced applications. Research in the form of ex-situ studies and theoretical modeling has been unsuccessful in developing a complete understanding of high temperature materials phenomenon. In-situ techniques have been plagued by experimental complexity, lack of resolution and thermal degradation effects. Further, insitu studies are typically performed in sterile environments questioning their ability to simulate real world environments and their interaction with the material. Environmental scanning electron microscopy combines the depth-of-field and high resolution advantages of conventional electron microscopy with novel gas based detection mechanisms, permitting observation of materials in a variety of gaseous atmospheres, at pressures as high as 20 Torr. Environmental scanning electron microscopy could provide researchers with a unique tool in dynamic high temperature investigations of materials and processes.

Recently researchers have been successful in performing in-situ studies at temperatures in excess of $1300^{\circ} \mathrm{C}$ [1-3]. Successful application of ESEM instrumentation in these regimes requires careful consideration and optimization of experimental conditions and equipment. The aim of this presentation will be to look at various aspects involved in optimizing and performing dynamic experiments at temperatures exceeding $1300^{\circ} \mathrm{C}$ in the ESEM.

Degradation of imaging conditions can result in loss of information and insight. Mechanically induced vibration can restrict experimental observations even at low temperatures. Thermal electron emission as the material is heated results in competing secondary emissions and poor signal detection conditions. At temperatures approaching and exceeding $1000^{\circ} \mathrm{C}$ this can result in complete signal loss. Careful optimization of electron beam parameters and bias voltages is necessary to maintain imaging under these conditions and will be discussed in detail. Contamination issues can result in modified high temperature behavior. Figure 1 show a bi-modal microstructure of a sample sintered in-situ in the ESEM. Possible explanations for this will be looked at. In-situ ESEM techniques must be free from beam specimen interactions in order to be able to use them in understanding high temperature processes and will be discussed in the presentation.

As an example we have used the ESEM to study high temperature behavior in industrially important barium titanate ceramics in the ranges between $1320^{\circ} \mathrm{C}$ and $1375^{\circ} \mathrm{C}$. An XL-30 ESEM FEG environmental scanning electron microscope in combination with a $1500^{\circ} \mathrm{C}$ hot-stage microfurnace has been used to perform the experiments. Results obtained from the in-situ studies will be compared and contrasted with those obtained using a conventional furnace under identical conditions.

\section{References}


[1] N. S. Srinivasan, Powder Technology, 124 (2002), 40-44.

[2] S. Subramaniam, R. Roseman, CT 157, $106^{\text {th }}$ ACER Proc., 2004, 97-104.

[3] S. Subramaniam, R. Roseman, M\&M Annual Meeting 2004 Proc.,

[4] S. Fischer, K. Lemster, R. Kaegi, J. Kuebler, B. Grobe, J. Elec. Micr., Vol. 53 no. 4, 2004, 393-396

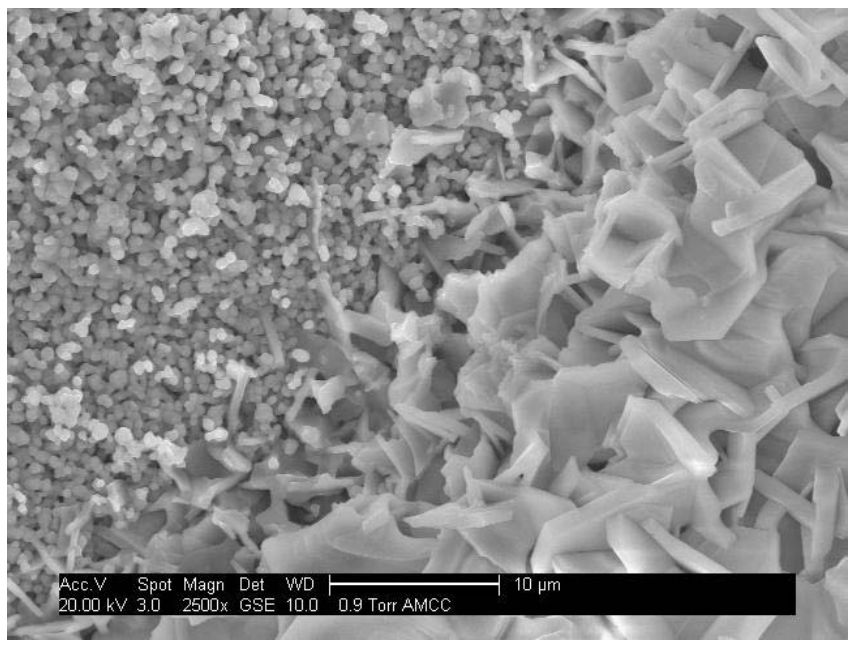

Figure 1. : ESEM micrograph on cooling of sample sintered in-situ in the ESEM at $1370^{\circ} \mathrm{C}$ exhibiting bimodal microstructure. 